\title{
GIBSON-GRAHAM, J. K. The end of capitalism (as we knew it): a feminist critique of political economy. Minneapolis: University of Minnesota Press, 2006. 348 p.
}

\author{
Patricia Kunrath Silva* \\ * Escola Superior de Propaganda e Marketing - Porto Alegre, RS, Brasil \\ patricia.kunrath@gmail.com \\ https://orcid.org/0000-0002-4821-5508
}


As geógrafas feministas Julie Graham e Katherine Gibson, que escrevem com a identidade autoral de J. K. Gibson-Graham, buscam desconstruir as noções de unidade, totalidade e singularidade tanto da economia quanto do capitalismo. Seu projeto - apesar de definirem-se como feministas marxistas (e entendendo o marxismo como plural) - possui uma forte base pós-estruturalista na tentativa da desconstrução de noções binárias tais como o capitalismo e o não capitalismo - especialmente representados nos projetos de pensadores de esquerda - nas imaginações de economias alternativas e outros mundos possíveis.

Tendo sido publicado pela primeira vez em 1996, a obra encontrou inúmeros comentaristas e críticos nas ciências sociais, tais como David Graeber (2010) e Bill Maurer (cf. Kunrath Silva, 2015), por exemplo. No prefácio à edição de 2006 as autoras destacam dentre essas críticas o perigo de que seu projeto seja ele mesmo entendido como colonialista. No entanto, partindo do trabalho colaborativo e aliança com movimentos locais, apostam que a transformação das condições de pobreza são feitas de baixo para cima, ou seja, protagonizada pelos próprios pobres.

As autoras apontam ainda que seus projetos estão "mais preocupados em teorizar as condições de possibilidade do que os limites para as possibilidades" (p. 25) ${ }^{1}$ identificando nas representações do capitalismo enquanto um sistema fechado, homogêneo, absoluto e inescapável - feitas muitas vezes por cientistas e intelectuais progressistas - as condições de sua própria força e reprodução. Teríamos assim criado a besta toda-poderosa contra a qual nos debatemos.

Correndo o risco de serem criticadas por seu otimismo, as autoras atentam para economias alternativas que existem em paralelo ao capitalismo, como nas iniciativas de cooperativas, microcréditos, economias solidárias, economias domésticas, entre outras. Elas sublinham o protagonismo do novo imaginário político emergente do movimento zapatista no México e do Fórum Social Mundial, que teria mobilizado o interesse acadêmico em economias alternativas e seus experimentos.

Ao tratar do encontro com pesquisadores e ativistas que se engajam em projetos conjuntos de trabalho como, por exemplo, no caso do Coletivo para Estudos de Organização Alternativa (Collective for Alternative Organisation

1 As traduções de todas as citações são minhas. 
Studies - CAOS) da University of Leicester Management Centre, as autoras destacam a condução dos trabalhos com "um espírito de abertura, mais do que no espírito negativo mais conhecido no qual cooptação, falha e incompletude são esperadas e confirmadas" (p. 7). Desafiando ainda análises que se centram no neoliberalismo ou no capitalismo, o que chamam de capitalocêntricas em analogia com teorias falocêntricas, Gibson-Graham propõem, a partir do conceito de sobredeterminação de Althusser, desconstruir o caráter essencialista aferido ao capitalismo.

Dessa forma, a noção de sobredeterminação na análise do capitalismo implica não mais aceitá-lo como um sistema total e fechado, mas sim como dinâmico, múltiplo e originado por uma pluralidade de fatores heterogêneos. Na mesma perspectiva da descentralização das análises da ideologia neoliberal e do capitalismo com algo dado, essencial, único e totalizante, no ano de 2015 a revista Cultural Anthropology publicou um dossiê de perspectiva feminista para estudos da ge(ne)ração do capitalismo ou generating capitalism (Bear; Ho; Tsing; Yanagisako, 2015a), contendo um manifesto para o entendimento de que o capitalismo possuiria gênero, performatividade e potencial de reinvenção constantes.

As autoras do manifesto "Gens: um manifesto feminista para o estudo do capitalismo", Laura Bear, Karen Ho, Anna Lowenhaupt Tsing e Sylvia Yanagisako (2015b), alinham-se a Gibson-Graham declarando que "nem a economia é uma lógica e nem o capitalismo é o seu veículo". Para elas, o fato de que "a economia é um foco de estudo aceito e relativamente limitado demonstra a naturalização de tais mundos construídos". Esse pensamento totalizante, contestado por alguns cientistas sociais, apesar de por vezes querer questionar o capitalismo "reproduz os sonhos capitalistas", e é o que Gibson-Graham chama de capitalocêntrico.

Para Gibson-Graham, dizer que a maior parte do discurso econômico é capitalocêntrica, significa que todas as dimensões de trocas econômicas, mesmo o que chama de "nanoeconomia" da vida diária, são vistas com relação ao capitalismo. E mais, as autoras fazem uma leitura de gênero e colocam em relação o discurso acerca do capitalismo e a cultura do estupro. Assim, o capitalismo seria o análogo do corpo masculino, "sujeito universal e espécie padrão do discurso falocêntrico", aparecendo como "o padrão econômico nos discursos que chamei de capitalocêntricos” (p. 35). 
As autoras apontam ainda a negação implícita da diferença sexual no falocentrismo, "já que a subjetividade humana toma uma forma singular... A mulher é constituída como menos do que humana já que ela é alteridade em relação ao homem" (p. 35). Na analogia do capitalocentrismo, o capitalismo seria "a forma econômica que se torna o modelo ou a definição de economia" (p. 35). Assim, "qualquer outra forma de economia falharia em se conformar a especificações realmente econômicas" (p. 35).

Cada um dos 11 capítulos do livro de Gibson-Graham apresenta-se como peça de um projeto de desconstrução de uma representação essencialista da economia e do capitalismo que afetam a realidade social por meio de sua performatividade. Recorrendo a uma miríade de autores, Gibson-Graham iniciam estabelecendo cinco estratégias centrais no primeiro capítulo para elaboração de práticas e suas respectivas representações não capitalistas: 1) "Construindo o espantalho", que consiste em atentar e analisar as ficções e os discursos que revestem o capitalismo de suas supostas coesão e homogeneidade; 2) "A desconstrução da relação capitalismo e não capitalismo" e 3) "Sobredeterminação enquanto uma prática antiessencialista"; 4) "Elaborando uma teoria da diferença econômica"; 5) "Contentando-se com os destroços e rudimentos", que apela para a "produção de conhecimento econômico dentro de (e desenvolvendo) um discurso de diferença econômica, e especificamente um discurso de classe".

O segundo capítulo, "Capitalismo e antiessencialismo: um encontro em contradição" foca-se em "métodos de desconstrução e desestabilização categórica" - assim como o décimo capítulo, intitulado "Capitalismo assombrado: fantasmas em um quadro preto". Ele explora o conceito althusseriano de sobredeterminação com o intuito de minar as certezas do conhecimento ocidental.

Intitulado "Classe e as políticas de identidade", o terceiro capítulo busca conceituar classe de forma não essencialista, "sugerindo uma gama de relações de classe não capitalistas na cena econômica contemporânea” (p. 250). Trata-se, por exemplo, "da entrada das mulheres no mercado de trabalho e o aumento de empregos de meio turno e temporários" (p. 46), levando esses sujeitos a não terem o trabalho - ou sua identidade professional - como central ou base primária de seu processo identitário social (Dubar, 2005). Percebem-se também políticas de identidade nas construções de movimentos sociais como o movimento feminista, LGBTQIA e no movimento negro, entre outros. Embora criticados por vezes como essencialistas, esses movimentos 
podem servir de pilar para a construção de identidades políticas. Mais referências e exemplos, como das mulheres australianas que trabalham em casa sob ordens de seus maridos em cidades de mineração e que as autoras consideram como produções feudais, são trazidos no capítulo 9, intitulado "Cortadores de bolo e gavetas de chá".

O quarto capítulo, “Como saímos desse lugar capitalista?", explora noções de espacialidade a partir das construções do "espaço social enquanto colônias do capitalismo e do falo, onde todos os objetos estão localizados e identificados com respeito a esses termos mestres" (p. 23). A representação feminista do espaço e do corpo fornecem possibilidades para imaginar espaços de diferença e talvez a geração de formas outras (para não chamar de não capitalista, recaindo no binômio, o que às vezes ainda acontece às autoras). Esse tema é retomado no capítulo 6 ("Inquirindo a globalização"), onde Gibson-Graham falam sobre a analogia do discurso do capitalismo, da globalização e da cultura do estupro já mencionada.

As autoras indicam ainda que cerca de $50 \%$ das atividades econômica que geram meios de subsistência no mundo - tanto em países ricos quanto pobres - estariam fora do escopo chamado capitalista. Esse dado chamaria a atenção para a "violência discursiva promulgada através de referências familiares às economias e sociedades 'capitalistas'" (p. 23).

No capítulo 5, ou em "A economia, estúpida! Discurso da política industrial e o corpo econômico", as autoras recorrem novamente a representações feministas do corpo a fim de desconstruir leituras organicistas, sistêmicas e unilineares de evolução que colocam o monismo econômico e o pináculo capitalista como pontos a serem alcançados. O capítulo 7, intitulado "Pós-fordismo enquanto política", segue a mesma linha argumentativa, analisando como discursos do fordismo e do pós-fordismo incorporaram (embody) a mesma noção totalizante da economia, bem como produziram um ativismo econômico atuando como "condições da reprodução capitalista" (p. 23).

O capítulo 8, "Rumo a uma nova classe política de distribuição", considera a empresa como "um ponto de coleta a partir do qual a riqueza é dispersada em inúmeras direções” (p. 23), e explora o capitalismo como uma diferença possível. Tendo assim o espaço capitalista como diferenciado e descentralizado, onde a exploração condensa riqueza, poder-se-ia começar a pensar contornos para uma nova classe política de distribuição. 
Para as autoras, o livro começa com o capítulo 11, "Esperando a revolução...", centrado em uma fala acerca do marxismo, na qual questionam a presença massiva de antagonismos ao capitalismo, mas um silêncio ainda significativo de propostas alternativas. Para elas, existem representações marxistas da teoria econômica que se tornaram mais "um obstáculo do que um estímulo a projetos políticos anticapitalistas" (p. 22).

Algumas das críticas que aparecem em relação ao livro tratam da ausência de propostas para o que deve ser construído no lugar do capitalismo e a falta de pesquisa empírica. De acordo com a resenhista Carolyn Gallagher (1997, p. 147):

[...] as políticas do livro [...] repousam em uma perspectiva teórica que não dá nenhuma garantia de que a desconstrução do capitalismo enquanto um conceito unificante levará necessariamente às formas progressistas de economia pelas quais elas esperam e clamam.

Para a autora, existem visões do marxismo que ainda perpassam e espreitam o trabalho, "deixando o leitor a imaginar o que pode e o que emergirá das ruínas" (Gallagher, 1997, p. 147). No entanto, considera notável a contribuição de Gibson-Graham tanto no escopo dos trabalhos pós-estruturalistas quanto feministas.

As pesquisa feministas tendem a se fixar ainda no corpo, saúde e sexualidade, esquecendo das dimensões econômicas destas mesmas representações. Espera-se que essas investigações comecem a crescer e parece que já assistimos a pequenas iniciativas nessa direção (veja-se como exemplo o "Gens manifesto" da Cultural Anthropology acima mencionado, embora ainda anglo-saxão) com o fomento de agências multilaterais a pesquisas e a grupos de economias alternativas e o que vem sendo convencionado chamar terceira onda do movimento feminista.

\section{Referências}

BEAR, L.; HO, K.; TSING, A. L.; YANAGISAKO, S. Generating capitalism. Theorizing the Contemporary: Fieldsights, 30 March 2015a. Disponível em: https://culanth.org/ fieldsights/series/generating-capitalism. Acesso em: 24 fev. 2018. 
BEAR, L.; HO, K.; TSING, A. L.; YANAGISAKO, S. Gens: a feminist manifesto for the study of capitalism. Theorizing the Contemporary: Fieldsights, 30 March 2015b. Disponível em: https://culanth.org/fieldsights/gens-a-feminist-manifesto-for-the-study-of-capitalism. Acesso em: 24 fev. 2018.

DUBAR, C. A socialização: construção das identidades sociais e profissionais. São Paulo: Martins Fontes, 2005.

GALLAGHER, C. Book review: J. K. Gibson-Graham's The end of capitalism (as we knew it): a feminist critique of political economy. Cambridge, MA: Blackwell, 1996. disClosure: A Journal of Social Theory, v. 6, p. 145-147, 1997.

GRAEBER, D. On the moral grounds of economic relations: a Maussian approach. [S.1.]: Open Anthropology Cooperative Press, 2010. (Working Papers Series 6).

KUNRATH SILVA, P. Entrevista com Bill Maurer. Horizontes Antropológicos, Porto Alegre, ano 22, n. 45, p. 395-408, 2016. Disponível em: http://www.scielo.br/pdf/ha/ v22n45/0104-7183-ha-22-45-0395.pdf. Acesso em: 24 fev. 2018. 